\title{
PHẪU THUẬT NỘI SOI TOÀN BỘ TIM ĐẬP \\ VÁ THÔNG LIÊN NHĨ Ở BỆNH NHÂN NŨ̉ 11 TUỔI
}

Đặng Quang Huy*, Nguyễn Ngọc Anh*, Lê Ngọc Thành*

\section{TÓM TẮT}

Hiện nay, đóng lỗ thông liên nhĩ (TLN) qua đường mở ngực nhỏ có nội soi (NS) hỗ trợ đã không còn xa lạ với nhiều người. Đóng lỗ TLN sử dụng phương pháp NS toàn bộ là kỹ thuật khó, đặc biệt khi thực hiện ở trẻ nhỏ. Chúng tôi báo cáo trường hợp bệnh nhân TLN 11 tuổi đã được phẫu thuật thành công bằng phương pháp NS toàn bộ tim đập.

Tì $\boldsymbol{k h} \boldsymbol{h} \boldsymbol{a}$ : phẫu thuật tim ít xâm lấn, NS tim toàn bộ, phẫu thuật tim đập

\section{TOTALLY ENDOSCOPY FOR ASD} REPAIR IN 11 YEAR-OLD GIRL

\section{SUMMARY}

Currently, closing atrial septal defect through video-assisted mini-thoracotomy isn't strange to many people. Totally endoscopic ASD closure is a difficult technique especially for children. We report the case of 11 year-old girl who underwent totally endoscopic atrial septal repair on perfused beating heart.

Keywords: Minimally invasive cardiac surgery, totally endoscopic, beating heart.

\section{I. ĐẶT VẤN ĐỀ}

Thông liên nhĩ (TLN) là bệnh tim bẩm sinh (TBS) thường gặp nhất, chiếm từ 6-10\% tộng số các dị tật TBS. Bệnh thường diễn biến âm thầm dẫn tới suy tim, tăng áp lực động mạch phổi nặng. Hơn 20 năm trở lại đây, tim mạch can thiệp là lựa chọn hàng đầu tại hầu hết các quốc gia trên thế giới với nhiều ưu điểm $[1,2]$. Mặc dù vậy vẫn còn nhiều dạng TLN không bịt được dù cũng như ngày càng có nhiều báo cáo về biến chứng lâu dài của bịt dù TLN khiến bệnh nhân phải mổ lại hoặc bị đe dọa tính mạng [3]. Phẫu thuật đóng TLN qua đường mổ cưa dọc xương ức và đường mở ngực nhỏ có NS hỗ trợ cho thấy còn nhiều mặt hạn chế. Trên thế giới chưa có nhiều báo cáo về mổ NS toàn bộ đóng TLN, đặc biệt ở trẻ nhỏ [4, 5]. Tại Việt Nam chưa có một công bố khoa học nào về việc áp dụng kỹ thuật mổ này. Vì lý do đó chúng tôi báo cáo trường hợp lâm sàng đầu tiên vá TLN NS toàn bộ tại Việt Nam.

\section{GIỚI THIỆU CA LÂM SÀNG}

Bệnh nhân nữ 11 tuổi được chẩn đoán TLN sau khi khám sức khỏe tại trường. Trẻ không có biểu hiện lâm sàng. Trên siêu âm tim trước mổ, lỗ TLN lớn đk $22 \mathrm{~mm}$, shunt trái phải, gờ động mạch chủ (ĐMC) và gờ tĩnh mạch chủ (TMC) dưới ngắn; đường kính tâm trương thất phải (TP) $30 \mathrm{~mm}$, đường kính tâm trương thất trái $27 \mathrm{~mm}$, áp lực động mạch phổi $45 \mathrm{mmHg}$, tăng lưu lượng máu qua van động mạch phổi với chênh áp tâm thu $18 \mathrm{mmHg}$ (hình $1 \mathrm{~B}, \mathrm{C}, \mathrm{D})$. Trẻ không có rối loạn nhịp trên điện tim, biểu hiện nhịp xoang $85 \mathrm{chu}$ kỳ/phút. Xquang phổi cho thấy chỉ số tim ngực tăng, nhiều máu lên phổi (hình $1 \mathrm{~A}$ ).

\footnotetext{
* Trung tâm Tim mạch, Bệnh viện E

Ngườ chịu trách nhiệm khoa học: GS.TS. Lê Ngoc Thành Ngày nhận bài: 15/10/2016 - Ngày Cho Phép Đăng: 05/11/2016 Phản Biện Khoa học: PGS.TS. Đặng Ngọc Hùng GS.TS. Bùi Đúc Phú
} 

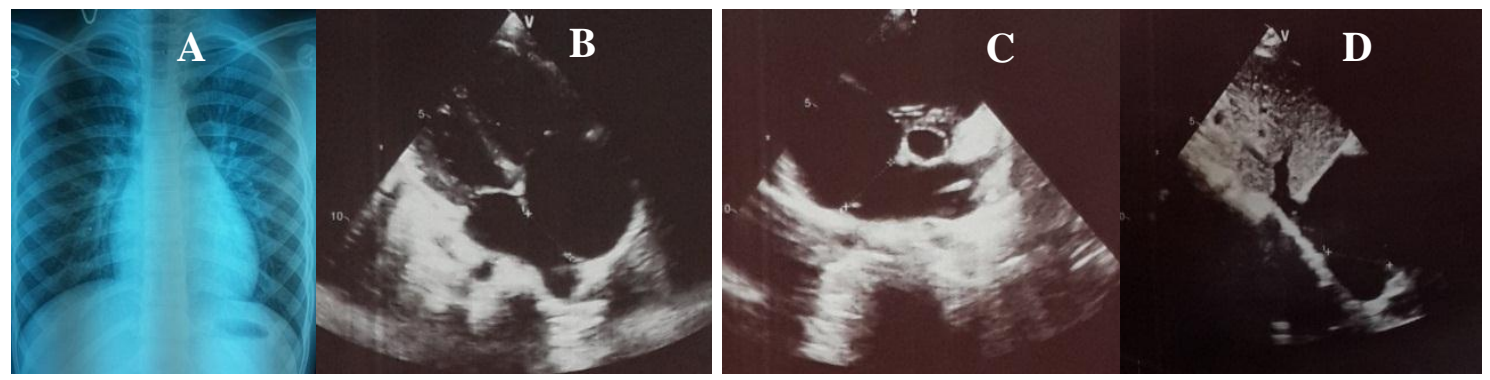

Hình 1: Cận lâm sàng trước mổ

A) hình ảnh nhiều máu lên phổi trên phim xquang; B) lỗ TLN lớn trên siêu âm qua thành ngực;

C) gò̀ ĐMC ngắn, D) gò̀ TMC dưới ngắn

Bệnh nhân được bịt dù bằng phương pháp tim mạch can thiệp, dù sau khi thả bám không chắc vào bờ lỗ thông, các bác sỹ can thiệp quyết định thu dù và hội chẩn mổ. Bệnh nhân được hội chẩn và quyết định phẫu thuật đóng lỗ TLN bằng phương pháp NS toàn bộ tim đập sau can thiệp 10 ngày.
Trong mổ, bệnh nhân được kê tư thế nghiên trái $30^{\circ}$, hai tay khép dọc theo thân, đầu bệnh nhân đặt nghiêng trái bộc lộ vùng cổ phải cho đặt cannula TMC trên trong mổ. Đặt bản điện cực chống rung ngoài hai bên xương bả vai (hình 2)

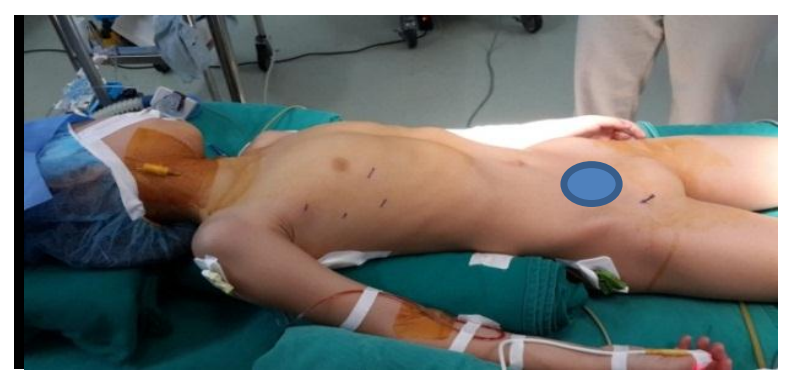

Hinh 2: Tu thế bệnh nhân

Thiết lập tuần hoàn ngoài cơ thể ngoại vi: cannula ĐM đùi gián tiếp qua đoạn mạch Dacron số 6 , cannula $\mathrm{TMC}$ trên và dưới qua $\mathrm{TM}$ cảnh trong phải và $\mathrm{TM}$ đùi phải theo phương pháp Seldinger (hình 3).

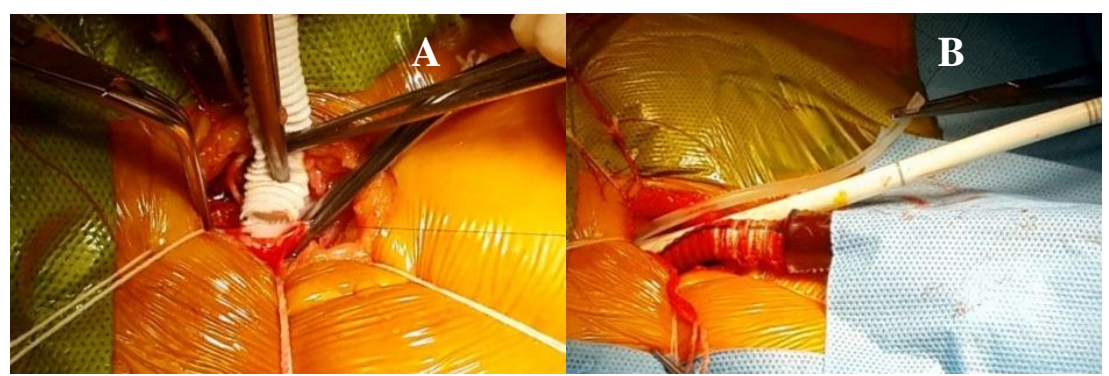

Hinh 3: Thiết lập tuần hoàn ngoài cơ thể ngoại vi

(A: Nối tận bên đoạn mạch nhân tạo với ĐM đùi chung của bệnh nhân. Sau đó nối đầu còn lại của mach nhân tạo với đường động mạch. B): Sau khi thiết lập xong đường ĐM (như trên mô tả) và cannula TMC duới qua TM đùi bằng phuoong pháp Seldinger). 
Đặt 04 Trocar trên thành ngực phải tại các vị trí đã được đánh dấu từ trước (hình 4), cụ thể là:

+ 01 Trocar 10mm tại khoang liên sườn (KLS) V đường nách trước cho tay phẫu thuật chính.

+ 01 Trocar $5 \mathrm{~mm}$ tại KLS $\mathrm{V}$ đường nách giữa cho đèn nội soi.

+ 01 Trocar $5 \mathrm{~mm}$ tại KLS III đường nách giữa cho tay phẫu thuật thứ hai.

+ 01 Trocar 5mm tại KLS VI đường nách giữa cho đường hút máu về máy tim phổi nhân tạo.

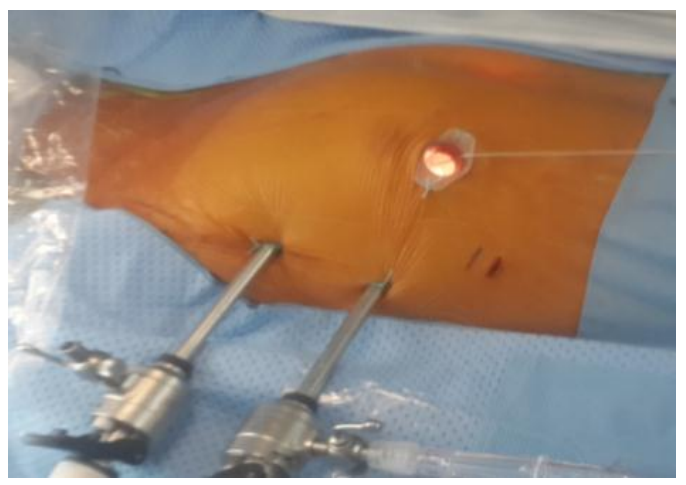

Hinh 4: Vị trí thiết lập các lỗ Trocar trên thành ngục

Bơm $\mathrm{CO} 2$ vào khoang màng phổi và màng tim, tốc độ bơm $\mathrm{CO} 2$ được kiểm soát bởi kỹ thuật viên chạy máy. Sau khi thắt $\mathrm{TMC}$ trên, nhĩ phải được mở dọc, máu trong tim được hút về bằng đường hút hỗ trợ để đảm bảo phẫu trường sạch máu. Tim vẫn đập trong suốt quá trình mổ, máu về liên tục qua lỗ xoang vành và các lỗ đổ trực tiếp trên thành nhĩ phải. Chúng tôi không dùng kim gốc ĐMC để đuổi khí cũng như không thắt
TMC dưới. TLN lỗ thứ phát đường kính $25 * 20 \mathrm{~mm}$, gờ ĐMC và gờ $\mathrm{TMC}$ dưới ngắn, không bất thường đổ về của các tĩnh mạch phổi. Vá lỗ TLN sử dụng miếng vá nhân tạo, khâu vắt, tăng cường bằng các mũi khâu rời (hình 5 ). Quá trình mổ được thực hiện qua hai trocar dưới màn hình NS. Sau đó nhĩ phải được đóng hai lớp, các công đoạn còn lại giống quy trình mổ NS hỗ trợ thông thường.

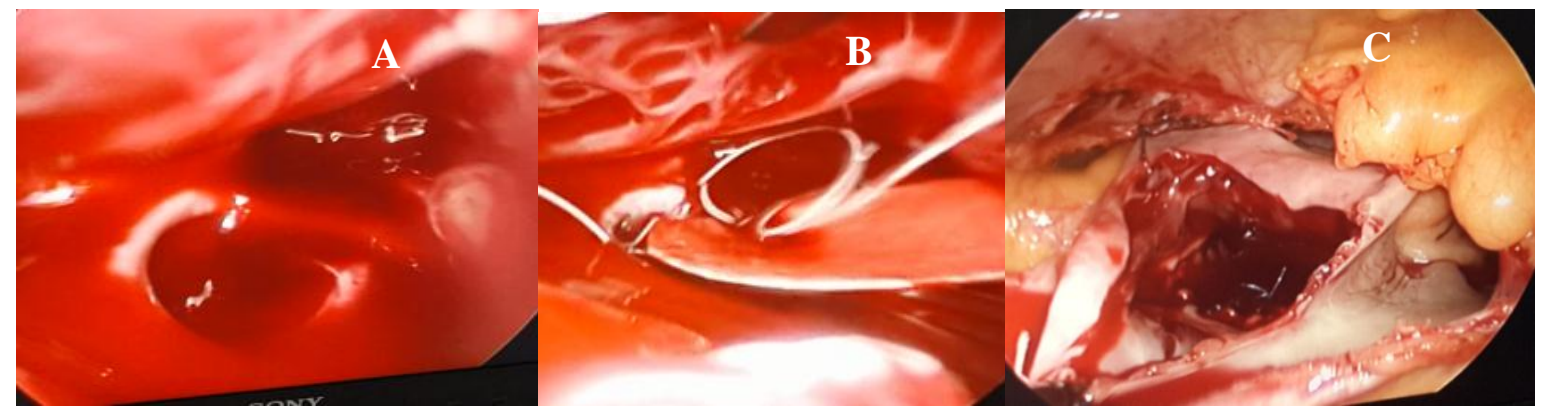

Hìn 5: Hình ảnh trước và sau vá TLN

(A: TLN lô̂ thứ phát, gò̀ ĐMC và TMC duới ngắn; B: Quá trình vá TLN qua NS; C: NP được khâu treo vào màng tim, lô̂ TLN đã được vá bằng miếng vá nhân tạo, kiểm tra toàn bộ đường khâu, khâu tăng cuờng tại nhũng vị trí cần thiết) 
Thời gian chạy máy 220 phút, bệnh nhân được rút nội khí quản sau mổ 11 giờ, nằm hồi sức 18 giờ, dẫn lưu màng tim và màng phổi ra $100 \mathrm{ml} /$ 24 giờ đầu. Bệnh nhân không phải dùng thuốc giảm đau từ ngày thứ 4 sau mổ và ra viện sau 7 ngày. Siêu âm tim qua thành ngực trước khi ra viện thấy lỗ thông được đóng kín, không shunt tồn lưu, đường kính TP đã giảm nhiều. Không có dấu hiệu liệt hoành trên phim Xquang tim phổi, chỉ số tim ngực giảm.

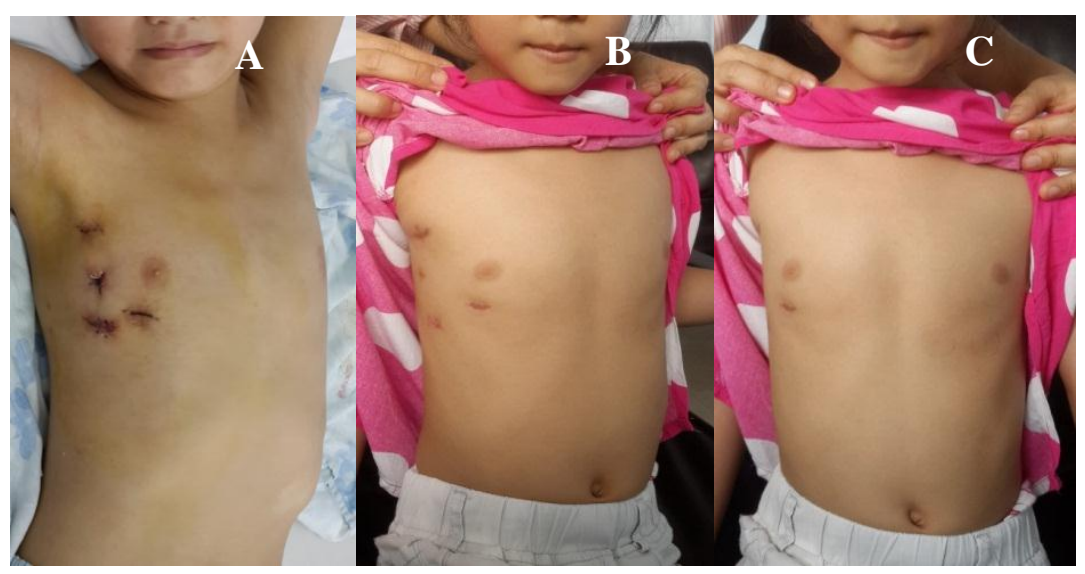

Hình 6: Kết quả sau mổ

(A: Sẹo ngay sau mổ, B, $C$ : sẹo sau mổ 1 tháng)

Sau 1 tháng khám lại, sẹo mổ bệnh nhân tốt, bệnh nhân trở lại sinh hoạt bình thường sau mổ 2 tuần. Gia đình và người bệnh hoàn toàn hài lòng về kết quả cuộc mổ.

\section{BÀN LUẬN}

TLN là bệnh TBS thường gặp nhất với tỉ lệ 2.5/1000 trẻ sinh ra sống, tỉ lệ này ngày càng tăng theo nghiên cứu của Van De Linde (2011) [6]. Tim mạch can thiệp hiện là lựa chọn hàng đầu trong điều trị TLN tại hầu hết các quốc gia trên thế giới với tỉ lệ thành công cao và rất an toàn. Tuy nhiên, ngày càng có nhiều nghiên cứu báo cáo về biến chứng lâu dài của bịt dù TLN như: huyết khối trong tim, loét thành vách tim, dị ứng Nikel, block dẫn truyền xuất hiện muộn... Bên cạnh những biến chứng đòi hỏi bệnh nhân phải mổ lại, có những tình huống lâm sàng đe dọa tính mạng người bệnh. Trong khi đó vá TLN bằng phương pháp phẫu thuật kinh điển cưa dọc xương ức hoặc qua đường mở ngực nhỏ còn nhiều hạn chế: bệnh nhân đau nhiều sau mổ, nguy cơ biến dạng lồng ngực, sẹo mổ xấu, sang chấn tâm lý sau mổ...[7]
Phẫu thuật NS toàn bộ vá TLN qua các lỗ chọc nhỏ trên thành ngực giúp khắc phục những hạn chế kể trên của phẫu thuật so với tim mạch can thiệp. Hiện nay trên thế giới chưa có nhiều báo cáo về phương pháp NS toàn bộ vá TLN. Các tác giả chủ yếu lựa chọn phương pháp liệt tim, thắt cả hai $\mathrm{TMC}$ để tạo phẫu trường sạch máu trong khi vá TLN; đối tượng bệnh nhân được lựa chọn hầu hết là người lớn. Khi kết thúc cuộc mổ, khí trong tim được loại trừ bằng hút kim gốc ĐMC $[4,5]$.

Với kinh nghiệm hơn 80 bệnh nhân phẫu thuật vá TLN tim đập qua đường mở ngực nhỏ có NS hỗ trợ, chúng tôi thực hiện ca phẫu thuật NS toàn bộ tim đập đầu tiên vá TLN trên bệnh nhân nhi 11 tuổi. Kết quả bước đầu thành công cho thấy đây là phương pháp phẫu thuật hứa hẹn có thể triển khai rộng trong tương lai gần góp phần nâng cao chất lượng điều trị bệnh tim bẩm sinh. 


\section{TÀI LIỆ THAM KHẢO}

1. Alobaidan, M., et al., Successful percutaneous closure of spiral atrial septal defect. Echo Res Pract, 2015. 2(1): p. K7-9.

2. Murakami, T., et al., Transcatheter closure of atrial septal defect protects from pulmonary edema: septal occluder device gradually reduces LR shunt. Heart Vessels, 2016.

3. Jalal, Z., et al., Long-term Complications After Transcatheter Atrial Septal Defect Closure: A Review of the Medical Literature. Can J Cardiol, 2016.

4. Yao, D.K., et al., Totally endoscopic atrial septal repair with or without robotic assistance: a systematic review and meta- analysis of case series. Heart Lung Circ, 2013. 22(6): p. 433-40.

5. Liu, G., et al., Totally thoracoscopic surgical treatment for atrial septal defect: midterm follow-up results in 45 consecutive patients. Heart Lung Circ, 2013. 22(2): p. 88-91.

6. van der Linde, D., et al., Birth prevalence of congenital heart disease worldwide: a systematic review and metaanalysis. J Am Coll Cardiol, 2011. 58(21): p. 2241-7.

7. Nagendran, J., et al., Minimally invasive endoscopic repair of atrial septal defects via right minithoracotomy. Multimed Man Cardiothorac Surg, 2016. 